\title{
Spill raises questions about radioactive materials in US
}

\section{Boston}

THE chance discovery of a small spill of radioactive material in a laboratory near Boston has raised questions about regulation of the use and disposal of lowlevel radioactive materials in the United States.

The spill was discovered when a radioactivity alarm was triggered by a truckload of trash about to be incinerated at a Boston dump. A company receipt in the contaminated garbage led state Department of Health investigators to Marshall Diagnostics, a small medical diagnostics company. There they found that six staff had unknowingly being working in the middle of a minor radioactivity spill, and had carried contaminants on their clothes into their homes and cars.

Louis W. Mead, the company's coowner, had spilled approximately two ounces of tungsten 178 - a radioactive material with a half-life of 21 days - in his laboratory. Mead, who explained he had been "too tired to think clearly", decided not to report the spill, and tried instead to clean it up himself with bleach and wet towels.

Cleaning materials, all unmarked, were then mixed in with the rest of the laboratory's garbage. Now, with the spill discovered, Mead's laboratory has been sealed off until the autumn when the radioactivity will have decayed to harmless levels. The laboratory shutdown has forced the company out of business.

The chance way the spill was discovered has raised questions about the efficiency with which the use of low-level radioactive materials is monitored. State officials admit they have too few staff to regulate effectively the 900 or so companies licensed by the state and are not even sure how many licences are still valid.

Massachusetts is not typical in choosing to regulate low-level radioactive materials itself; most states leave arrangements to the Nuclear Regulatory Commission (NRC). Karl Abraham, NRC spokesman, stressed that all of the 13,000 institutions licensed by NRC and the additional 10,000 institutions licensed by states to handle low-level radioactive materials, including hospitals, universities and private laboratories, are required to dispose of these materials in appropriately marked containers and ship them to appropriately licensed burial grounds.

But with only 260 NRC inspectors nationwide overseeing the handling of all nuclear waste, some of them located permanently at nuclear power plants, compliance can hardly be guaranteed.

Abraham acknowledged that many of

\section{Advances in superconducting fibres using lasers}

\section{Berkeley}

STANFORD's Center for Materials Research last week announced an advance that may lead to superconducting wires which are flexible and capable of high current density at relatively high temperature.

Wires would be made from fibres produced by using a laser to melt the top of a ceramic rod of bismuth-strontiumcalcium-copper oxide. A seed crystal is introduced into the melted spot and then drawn out to form a thin fibre containing aligned crystal grains.

Robert Feigelson, director of the Crystal Science Department, said there is no theoretical limit to the length of fibres and that preliminary tests have shown them to be "quite flexible". The technique has produced single crystals $8 \mathrm{~mm}$ in length. The dense, aligned structure and longer length of the crystals promise to minimize the weak links at grain boundaries that limit current flow in ceramics with non-aligned crystals.

A 1-cm-long fibre produced by the laser technique has sustained a current flow of 30,000 amps per $\mathrm{cm}^{2}$ at $4 \mathrm{~K}$. Feigelson
Says, and probably would have done even better if a contact had not failed. While that current density is greater than has been reported in bulk materials at $4 \mathrm{~K}$, the important question of current density at $77 \mathrm{~K}$ has not yet been addressed.

To be commercially useful, hightemperature superconductors must support current densities close to 1 million amps per $\mathrm{cm}^{2}$, a goal that has been achieved in thin films, but has not yet been approached in fibres. Researchers at AT\&T Bell Laboratories recently reached a critical current density of 17,000 amps per $\mathrm{cm}^{2}$ with an yttrium-barium-copper oxide fibre in which grains were aligned by melt-textured-growth.

But Sungho Jin at Bell Laboratories called Stanford's laser method an important advance, and agreed with the Stanford group that improvements in grain alignment in fibres should lead to commercially useful critical current densities.

Meanwhile, Stanford attorneys are seeking a patent for the laser process. which will be published this summer in Science.

Marcia Barinaga the institutions using small quantities of low-level materials are inspected only every four or five years. Even at larger institutions, however, compliance does not always meet expectations. A little over a year ago, Harvard University was cited for a dozen violations in its handling of low-level radioactive materials in a surprise NRC inspection and was fined $\$ 10,000$. Inspectors found that researchers had disposed of low-level radioactive materials down the drain.

Seth Shulman

\section{Zero resistance in Japanese research}

\section{Tokyo}

JAPANESE researchers have developed a technique for making the highest-temperature phase of the new bismuth superconductors which yields stable samples of quite high purity. The bismuth-strontiumcalcium-copper oxide superconductors discovered by Hiroshi Maeda of Japan's National Research Institute of Metals a few months ago are now believed to have three phases with zero-resistance temperatures $\left(T_{\mathrm{c}}\right)$ of about $80 \mathrm{~K}, 90 \mathrm{~K}$ and $105 \mathrm{~K}$ (see Nature 333, 153; 1988). But it has been impossible to prepare pure samples of the highest-temperature phase, and the $T_{\mathrm{c}}$ of mixed-phase samples containing the high$T_{\mathrm{c}}$ phase tends to decrease when an electric current is passed through the samples.

Now a joint group of researchers at Kyoto and Okayama universities claim to have prepared 85-90 per cent pure samples of the $105-\mathrm{K}$ phase by incorporating small amounts of lead in the samples and by using metal oxalates rather than oxides in the preparation process. The samples show zero resistance at $107 \mathrm{~K}$ and maintain this transition temperature even when currents of 2-200 mA per $\mathrm{cm}^{2}$ are repeatedly applied.

According to Monday's issue of Nikkei Superconductor, Dr Mikio Takano of Kyoto University's Institute for Chemical Research believes that the lead partially replaces bismuth in the samples, but this has yet to be proved. Most of the lead is lost during preparatory heating (inductively coupled plasma atomic emission spectrophotometry indicates a $\mathrm{Bi}: \mathrm{Pb}: \mathrm{Sr}: \mathrm{Ca}: \mathrm{Cu}$ ratio of $65: 5: 100: 85: 180$ ), but if the lead is reduced the percentage of the hightemperature phase decreases. On going to press, details were to be reported on Wednesday at a conference in Tokyo.

Almost simultaneously with this announcement, NEC Corporation claimed to have developed a thin film of the hightemperature phase which also shows zero resistance at $107 \mathrm{~K}$ - the highest temperature so far reported for a thin film of bismuth superconductors. But in NEC's case, the purity of the phase in the film is only about 50 per cent. 